forcings (for an overview see, e.g. Widmann and Tett 2003). Because of internal variability, the forcing factors do not completely determine the state of the system, and thus a transient forced run will yield only one of many possible realizations of the climate that are consistent with the forcing. Assimilation simulations attempt to also include part of the historic internally generated variability and compensate for model deficiencies. Data assimilation into atmospheric GCMs has been operationally employed for numerical weather prediction and atmospheric reanalyses using sophisticated methods, as well as for process studies and model validation using the simpler nudging method, which directly forces the model states towards prescribed target values. To adapt nudging to paleoclimatic applications, where the climate estimated from proxy data is relatively uncertain, DATUN was developed. The first step is the estimation of large-scale climate states through upscaling, as described above. The second step will employ a newly developed pattern nudging technique to nudge the model state towards the estimated large-scale states, without directly affecting components of the climate state that are not constrained by proxy data, and without suppressing synoptic-scale variability.

In test experiments, the ECHAM4 atmospheric GCM was nudged towards constant target amplitudes of the AO. Instead of directly nudging the model SLP towards the AO pattern (Fig. 1c), the relative vorticity of the wind field was nudged throughout the lower half of the troposphere towards the AO vorticity signal (not shown), which was defined by regression maps (Widmann 2004). The amplitudes of the vorticity pattern can be modified as desired (Fig. 1f), the SLP response to the nudging shows the $A O$ structure and the specified amplitude (not shown), and stormtracks are modified in a physically plausible way without being suppressed (Fig. 1 d/e). Experiments using a coupled atmosphere-ocean GCM and historic values of largescale anomalies are in preparation.

\section{REFERENCES}

Jones, J. M. and Widmann, M., 2003: Instrumentand tree-ring-based estimates of the Antarctic Oscillation. J. Climate 16: 3511-3524.

Jones, J. M. and Widmann, M., 2004: Reconstructing large-scale variability from palaeoclimatic evidence by means of Data Assimilation Through Upscaling and Nudging (DATUN). In: Fischer, $H_{\text {., }}$ Kumke, T., Lohmann, G., Flöser, G., Miller, H., von Storch, H., and Negendank, J. F. W. (eds.), 2004: The KIHZ project: towards a synthesis of Holocene proxy data and climate models. Springer, Heidelberg, Berlin, New York. ISSN 1437-028X.

Jones, P. D. and Mann, M. E., 2004: Climate over Past Millennia. Reviews of Geophysics, 42: RG2002/ 2004

Widmann, M., 2004: One-dimensional CCA and SVD, and their relationship to regression maps. J. Climate, in revision.

Widmann, M. and Tett, S. F. B., 2003: Simulating the climate of the Last Millennium.PAGES Newsletter: 11(2/3), 21-23

For full references please consult:

www.pages-igbp.org/products/newsletters/ref2004_2.html

\title{
Solar Variability and Holocene Climate: Evidence from Radiocarbon, Tree-Ring Proxies and Climate System Modeling
}

\author{
B. Kromer ${ }^{1}$, M. Claussen $^{2}$, N. Latuske ${ }^{1}$, M. LüKen ${ }^{2}$, S. Remmele ${ }^{1,4}$ and G. Schleser ${ }^{3}$ \\ ${ }^{1}$ Heidelberger Akademie der Wissenschaften, Institut für Umweltphysik, INF 229, 69120 Heidelberg; bernd.kromer@iup.uni-heidelberg.de \\ 2Potsdam Institut für Klimaforschung, Telegrafenberg A31, 14473 Potsdam \\ Institut für Chemie und Dynamik der Geosphäre, Forschungszentrum Jülich GmbH, 52425 Jülich, \\ ${ }^{4}$ Institut für Botanik-210, Universität Hohenheim, 70595 Stuttgart, Germany
}

Solar forcing of climate is a longstanding unresolved issue. Eddy (1976) was among the first to postulate a link between a widespread cooling event and a low level of solar activity, suggested by the absence of sunspots in the $17^{\text {th }}$ century (Maunder minimum). Prior to visual observations of solar activity, only cosmogenic isotopes, such as ${ }^{14} \mathrm{C},{ }^{10} \mathrm{Be}$ and ${ }^{36} \mathrm{Cl}$, preserved in well dated archives, provide proxy information for solar heliomagnetic activity. Their production rate depends on the shielding of the Earth by the magnetic field around the Earth, i.e. the superposition of the Earth's dipole moment and the solar wind (Masarik and Beer 1999).

In our project within DEKLIM, we focus on the reconstruction of solar activity using the decadal to century-scale fluctuations in

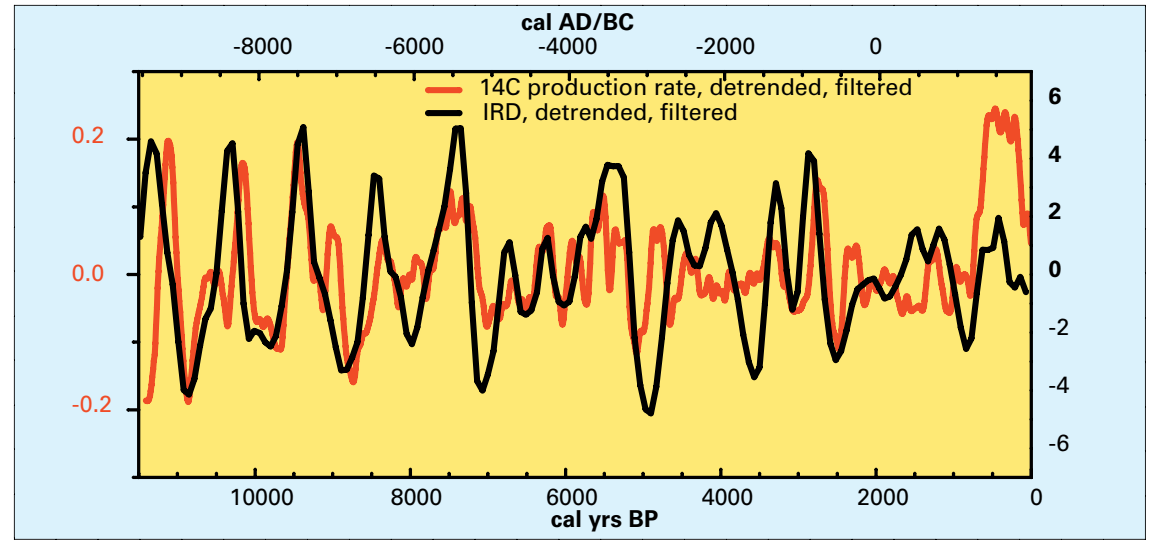

Fig. 1: Changes in ${ }^{14} \mathrm{C}$ production rate (difference to long term trend, unit is atoms $/ \mathrm{cm}^{2} / \mathrm{sec}$ ) compared to the percentage of hematite stained grains in North Atlantic cores MC52, V29191, V2381 (for details and locations see Bond et al. 2001). The ${ }^{14} \mathrm{C}$ production has been calculated using an Oeschger-Siegenthaler carbon box model, from $\Delta^{14} \mathrm{C}$ in IntCal98 (Stuiver et al. 1998) and new extensions. The data sets are low-pass filtered, and detrended to remove the longterm trend. Cooling events throughout the Holocene are coincident with intervals of low solar activity (high ${ }^{14} \mathrm{C}$ production rate).

atmospheric ${ }^{14} \mathrm{C}$ levels of the past 12,000 years, and investigate climate proxies in tree-rings during intervals of quiet and active sun.
The ${ }^{14} \mathrm{C}$ level in the past is obtained from high-precision ${ }^{14} \mathrm{C}$ analyses of decadal tree-ring sections, and ${ }^{14} \mathrm{C}$ production is then calculated 


\section{Science Highlights: DEKLIM}

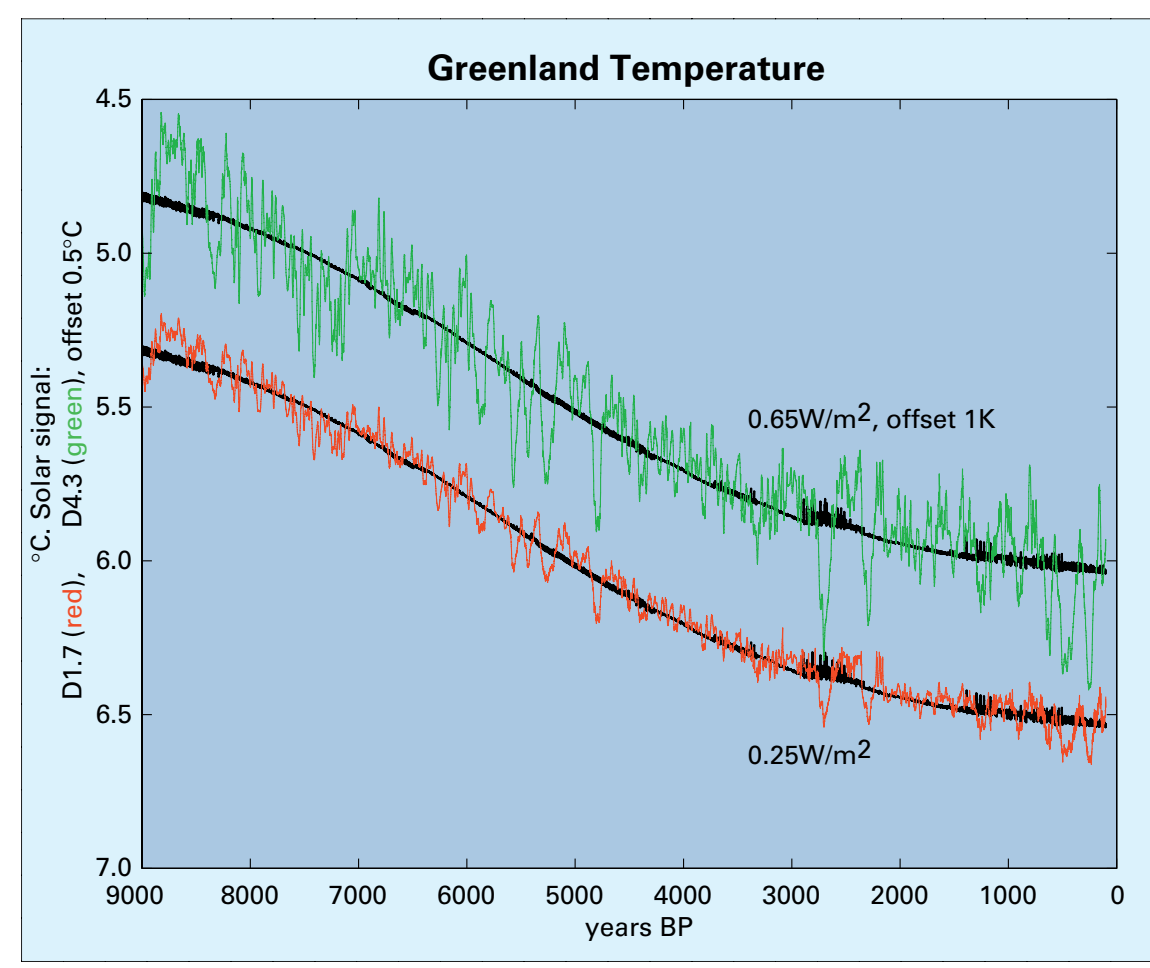

Fig. 2: Surface air temperature in the North Atlantic area encompassing Greenland for the past 9,000 years, as modeled by CLIMBER-2. The control runs (black lines) are compared to runs including solar irradiance changes, based on a parameterization by ${ }^{14} \mathrm{C}$ production rate changes, as shown in Figure 1 (red curve). Two scalings are shown, equivalent to a change in irradiance of $0.24 \%$ and $0.65 \%$ between the Maunder minimum and the present.

using a simple carbon box model of atmosphere/biosphere, ocean mixed layer and deep ocean. The data is complemented by a modeling exercise, in which the climate system model CLIMBER-2 is forced by solar irradiance changes that are parameterized by the ${ }^{14} \mathrm{C}$ production changes.

We recently found compelling evidence for solar forcing of cooling events in the North Atlantic sector (Bond et al. 2001) by comparing ice-drift indices to the productionrate fluctuations of ${ }^{14} \mathrm{C}$ and ${ }^{10} \mathrm{Be}$ (Fig. 1). The de-trended ${ }^{14} \mathrm{C}$ production signal was obtained from the ${ }^{14} \mathrm{C}$ data set of INTCAL98 (Stuiver et al. 1998) and extensions of the German oak and pine chronology (Friedrich et al. 2001) back to 12,400 cal BP, carried out as part of our work in DEKLIM. In the decadal to century time-window, the ${ }^{14} \mathrm{C}$ signal is considered to be caused mainly by heliomagnetic modulation of the ${ }^{14} \mathrm{C}$ production. However, an additional oceanic contribution, via changes in uptake of $\mathrm{CO}_{2}$ cannot be ruled out completely, although the magnitude of putative ocean ventilation changes would have to be large. Furthermore, the strong correlation to the ${ }^{10} \mathrm{Be}$ signal in Greenland ice-cores (Muscheler et al. 2003) points to the sun as the common dominant source of the observed variations in the concentration of the cosmogenic isotopes.

Using ${ }^{14} \mathrm{C}$ as a proxy of solar activity (high production indicating low heliomagnetic activity and vice versa), we are studying climate proxies in the tree-rings of the German oak and pine chronologies, comparing intervals of quiet and active sun. So far, we have performed time-series analysis of the data sets using the SSA toolkit and have investigated stable isotopes ${ }^{13} \mathrm{C}$ and ${ }^{18} \mathrm{O}$ from whole wood and cellulose, as well as growth indicators (ring width of early and late wood, mean sensitivity, and indicators of fluvial activity in the Rhine, Main and Danube River area from the deposition and germination of trees). For the interval studied so far, the variance of the latewood thickness (mean sensitivity) and the similarity index ('Gleichläufigkeit') to solar activity, especially for the $8^{\text {th }}$ century BC interval of extremely low solar activity, a cool and wet appear to be inversely correlated episode in some regions of Central Europe (van Geel et al. 1998).

Carbon and oxygen isotopes were analyzed in tree rings from periods showing strong variations in solar activity, such as from 11,310 to $10,880 \mathrm{BP}$ (German pine chronology), and from 4,900 to $4,700 \mathrm{BP}$ and 2,930 to 2,570 BP (German oak chronology). The early Holocene record is striking in view of the dramatic $\Delta^{13} \mathrm{C}$ declines and subsequent recoveries observed. Rather smooth sections alternate with strong variations of up to almost $4 \%$ o. A similar behavior is documented for the oxygen isotopes, though the variations do not correlate with those from the carbon isotopes. As expected and noted earlier (Schleser et al. 1999), the information from ${ }^{13} \mathrm{C}$ and ${ }^{18} \mathrm{O}$ is complex, with strong contributions from physiological processes within the tree, not directly related to external climate forcing.

However, compelling the observed correlations may appear (e.g. a sustained match over many manifestations of the process, as seen in Figure 1), any suggestion of a solar component of natural climate variability must be backed by climate system modeling. Therefore, we created time series of solar irradiance scaled with respect to the ${ }^{14} \mathrm{C}$ production changes (Bard et al. 2000; Crowley 2000) for the full Holocene interval, and used them as input for the climate system model of intermediate complexity, CLIMBER-2 (Petoukhov et al. 2000, Ganopolski et al. 2001). This model has been used for transient simulations of Holocene climate change (Claussen et al. 1999), as well as studies of the sensitivity of the climate system to changes in natural and anthropogenic forcings, i.e., changes in insolation, volcanic activity, land use and greenhouse gas emissions during the last 1,000 years (Bauer et al. 2003).

Figure 2 and 3 are showing results for two scalings of the ${ }^{14} \mathrm{C}$ production change to irradiance change, equivalent to an increase of solar irradiance of $0.24 \%$ and $0.65 \%$ (corresponding to a change of insolation at the top of the atmosphere of 3.3 and $8.9 \mathrm{~W} / \mathrm{m}^{2}$, respectively) 


\section{Science Highlights: DEKLIM}

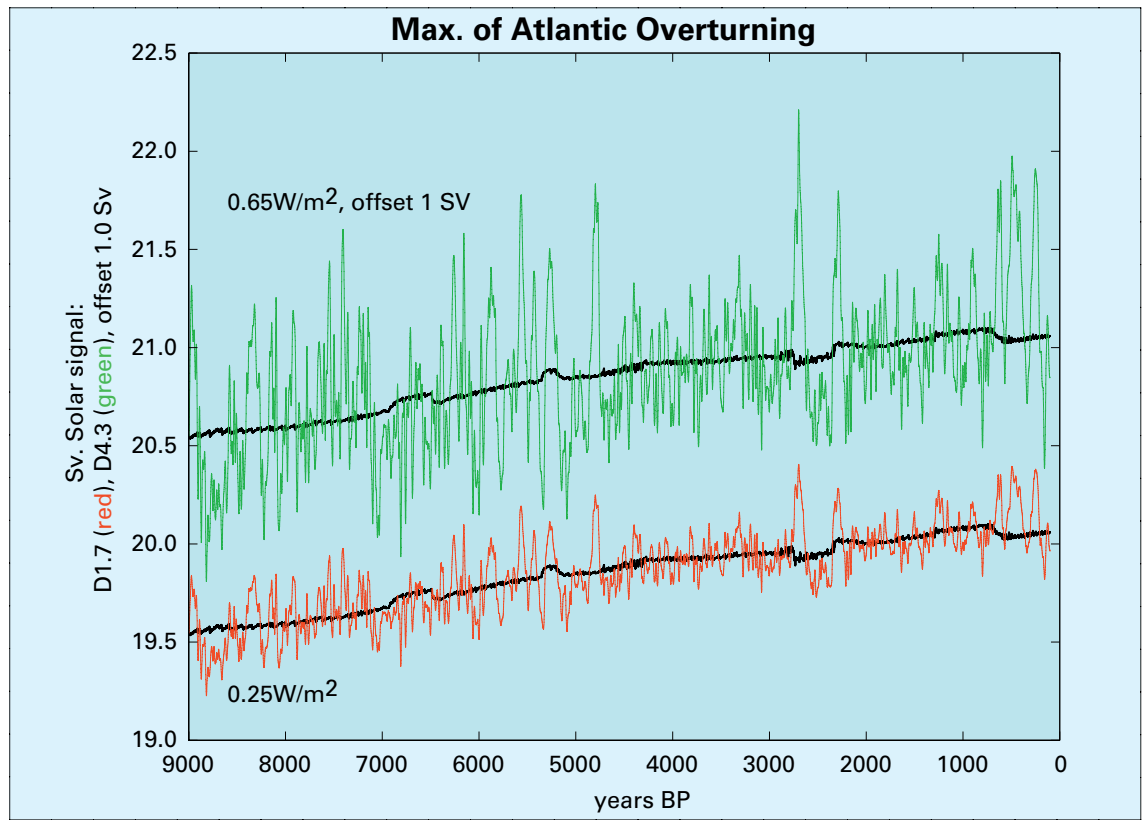

Figure 3: Maximum of North Atlantic overturning for the past 9,000 years, modeled by CLIMBER-2. The control runs (black lines) are compared to runs including solar irradiance changes, based on a parameterization by ${ }^{14} \mathrm{C}$ production rate changes, (Figure 1, red curve). Two scalings are shown, equivalent to a change in irradiance of $0.24 \%$ and $0.65 \%$ between the Maunder minimum and the present

between the Maunder minimum and the present (Lean et al. 1995, Reid 1997). The atmospheric temperature in the North Atlantic area of CLIMBER-2 encompassing Greenland shows a linear, positive response to irradiance changes of 0.2 and $0.6^{\circ} \mathrm{C}$, respectively, whereas the stream function is inversely re- lated to solar forcing (overturning is enhanced during cooling events). Since CLIMBER-2 reveals no free decadal and centennial variability, the response of the climate system to changes in solar forcing is clearly seen in the model results. There appear to be some larger temperature excursions in response to solar variability, for example in the $3^{\text {rd }}$ and $5^{\text {th }}$ millennium $B P$, which could be as large as the climate changes in the Maunder and Spörer minima of the last millennium.

\section{REFERENCES}

Bard, E., Raisbeck, G., Yiou, F. and Jouzel, J., 2000 Solar irradiance during the last 1200 years based on cosmogenic nuclides. Tellus 52B, 985-992.

Bauer, E., Claussen, M., Brovkin, V. and Huenerbein, A., 2003: Assessing climate forcings of the Earth system for the past millennium. Geophys. Res. Lett. 30 (6), 1276, doi:10.1029/2002GL016639, 2003.

Bond, G., Kromer, B., Beer, J., Muscheler, R., Evans, M., Showers, W., Hoffmann, S., Lotti-Bond, R., Hajdas, I. and Bonani, G., 2001: Persistent Solar Influence on North Atlantic Surface Circulation During the Holocene. Science 294, 2130-2136.

Friedrich, M., Kromer, B., Kaiser, K.F., Spurk, M., Hughen, K.A., and Johnsen, S.J., 2001: High resolution climate signals in the Bølling/Allerød Interstadial as reflected in European tree-ring chronologies compared to marine varves and ice-core records. Quaternary Science Reviews 20 (11), 1223-1232

Schleser, G.H., Helle, G., Lücke, A., and Vos, H., 1999: Isotope signals as climate proxies: the role of transfer functions in the study of terrestrial archives. Quaternary Science Reviews 18 (7) 927-943.

For full references please consult:

www.pages-igbp.org/products/newsletters/ref2004_2.htm

\section{Simulation of the 0xygen Isotope Ratio in Foraminiferal Carbonate During Heinrich Event 1: A Climate Model-Data Comparison}

\section{A. Paul and S. Mulitza \\ Fachbereich Geowissenschaften und DFG-Forschungszentrum 'Ozeanränder', Universität Bremen, 28334 Bremen, Germany; apau@palmod.uni-bremen.de}

The oxygen-18/oxygen-16 isotope ratio preserved in fossil carbonate shells of planktic and benthic foraminifera $\left(\delta^{18} O_{c}\right)$ is one of the most important proxies in paleoclimatology. First, oxygen isotopes in general circulate through all components of the climate system (atmosphere, ocean and ice) and are fractionated whenever a phase transition occurs. Second, $\delta^{18} \mathrm{O}_{c}$ in particular has been measured on a vast number of ocean sediment cores with high precision. Since a temperature-dependent fractionation of about $0.2 \% /{ }^{\circ} \mathrm{C}$ occurs during the formation of carbonate tests in foraminiferal shells, changes in $\delta^{18} \mathrm{O}_{\mathrm{c}}$ contain the clue for both changes in the temperature and the oxygen-18/oxygen-16 ratio of the ambient seawater $\left(\delta^{18} \mathrm{O}_{\mathrm{w}}\right)$.

This opens up a unique opportunity to combine climate models and a wealth of paleoclimatic data: If oxygen isotopes are transported in an ocean model (e.g., Paul et al., 1999; Schmidt, 1999; Delayge et al., 2000; Paul and Schäfer-Neth, 2004), the isotopic composition of carbonate can be directly simulated. As a by-product, the relative importance of changes in seawater $\delta^{18} \mathrm{O}$ and temperature can be assessed. By improving the match to the reconstructed climate history, a better understanding of the climate system can be gained.This, as well as the prospect of reducing uncertainties in forecasting future climate changes, lies at the heart of the DEKLIM program.

Like the two related DEKLIMPaleo projects 'CliTrans' and 'Palaeo Isotopes', our 'Oxygen Isotopes' project focuses on the climate transition from the Last Glacial Maximum (LGM) to the Holocene (the last deglaciation). Here our special interest is on the oxygen isotope data from the Atlantic Ocean for the LGM and Heinrich Event 1 (H1), which reflect the extent and speed of climate change during this period. For the first time we employed a climate model of reduced com- 